\title{
Preoperative biopsies as predictor for the necessity of inguinal lymph node surgery in squamous cell carcinoma of the vulva-a retrospective tertiary center analysis
}

\author{
Caroline Pahmeyer ${ }^{1}\left(\mathbb{D} \cdot\right.$ Fabinshy Thangarajah $^{1} \cdot$ Dominik Ratiu $^{1} \cdot$ Anne Maria Schultheis ${ }^{2}$. \\ Birgid Schömig-Markiefka ${ }^{2} \cdot$ Peter Mallmann ${ }^{1} \cdot$ Bernd Morgenstern ${ }^{1}$
}

Received: 28 March 2020 / Accepted: 14 May 2020 / Published online: 7 June 2020

(c) The Author(s) 2020

\begin{abstract}
Purpose Squamous cell carcinoma of the vulva (SQCV) is the fifth common cancer in women. Necessity of inguinal lymph node surgery depends on the depth of stromal invasion, inducing lymph node surgery, if depth of invasion is more than $1 \mathrm{~mm}$. In this study we tested the prediction of stromal infiltration depth by measurements in preoperative biopsies.

Methods We analyzed whether a different operative strategy in respect to lymph node surgery would have been chosen based on the pre- or postoperative depth of stromal invasion for each patient. Examination of infiltration depth in preoperative biopsies and surgical specimen were compared.

Results In total 77 patients were included in this study. Of those $89.6 \%$ showed different depths of stromal invasion comparing the pre- and postoperative specimen. Within seventeen patients (22.1\%) preoperative depth was $1 \mathrm{~mm}$ or less and a postoperative depth was $>1 \mathrm{~mm}$.

Conclusion We pointed, that only in $77.9 \%$ of the patients who should have undergo lymph node surgery based on the postoperative depth of infiltration underwent this procedure. Consequentially in $22.1 \%$ of the cases a second operation could not be prevented with a preoperative taken biopsy as indicator for the necessity of lymph node surgery.
\end{abstract}

Keywords Vulvar cancer · Preoperative biopsies · Inguinal lymph node biopsies · Depth of infiltration

\section{Introduction}

One of the greatest factors in reducing mortality of vulva cancer is an appropriate treatment of inguinal lymph nodes (Thangarajah et al. 2019). If the inguinal lymph nodes are clinically suspicious, a systematic inguinal lymphadenectomy is recommended. Following guidelines (AWMFLeitlinie Stand 2015; Koh et al. 2017; Oonk et al. 2017;

Caroline Pahmeyer, Fabinshy Thangarajah equally contributed.

Caroline Pahmeyer

Caroline.pahmeyer@uk-koeln.de

Fabinshy Thangarajah

fabinshy.thangarajah@uk-koeln.de

1 Department of Obstetrics and Gynaecology, Medical Faculty, University Hospital Cologne, Kerpener Straße 34, 50931 Cologne, Germany

2 Department of Pathology, University Hospital Cologne, Kerpener Straße 62, 50937 Cologne, Germany
RCOG 2014), the indication for operative staging of the inguino-femoral lymph nodes in early stage disease depends on the stromal invasion. Infiltration of $1 \mathrm{~mm}$ or less is rarely associated with inguinal node metastases, whereas infiltration depth of 1 or more mm should be treated with lymph node surgery to reduce mortality (AWMF-Leitlinie Stand 2015). Depending on further factors this can be performed as sentinel lymph node biopsy (SNB) or systematic inguinofemoral lymphadenectomy. Following German and international guidelines, a diameter of less than $4 \mathrm{~cm}$ of the unifocal tumor, no clinical suspicious lymph node, informed patient consent and compliance to close follow-up are eligibility criteria for SNB (AWMF-Leitlinie Stand 2015; Koh et al. 2017; Oonk et al. 2017; RCOG 2014). In addition, only appropriately trained surgeons should perform this procedure (AWMF-Leitlinie Stand 2015). In case of midline tumors a bilateral groin node dissection is recommended.

To reduce the morbidity of a second operation, preoperative biopsies are taken into consideration not only to confirm 
the diagnosis of vulva cancer but to determine the need for lymph node surgery depending on the depth of infiltration.

Within this investigation, we took a closer look into the reliability of preoperative biopsies and scrutinized its qualification as indicator for the necessity of lymph node surgery in vulva cancer.

\section{Methods}

Patients with histologically proven SQCV treated in the University Hospital Cologne between 2005 and 2019 and with available preoperative punch biopsies were taken into consideration within this study. Patients underwent primarily surgery of the vulva with or without lymph node surgery depending on preoperative diagnostics. Patients with a depth of infiltration $\leq 1 \mathrm{~mm}$ in the preoperative biopsy and $>1 \mathrm{~mm}$ within the surgical specimen were treated with secondary lymph node surgery. Examination of infiltration depth in biopsies and surgical specimen were compared. A relevant difference between two depths of infiltration was defined in cases with at least $1 \mathrm{~mm}$ discrepancy. Patients characteristics were assessed and analyzed. Patients with preoperative VIN status and postoperative diagnosed invasive vulva cancer were included also.

\section{Results}

In total, 77 patients were included into this study. The mean age was 56.4 years within the study cohort, while mean BMI was $27.5 \mathrm{~kg} / \mathrm{m}^{2}$. Both characteristics were within the expected range (Alkatout et al. 2015; Brinton et al. 2017).

The majority of patients showed pT1b tumors $(70.1 \%$, $n=54)$ and were nodal negative $(76.6 \% n=59)$. In total, $76.6 \%$ of the patients had G2 tumors. Table 1 shows an overview of patient's characteristics. Preoperatively $37.7 \%$ $(n=29)$ showed an infiltration depth of $\leq 1 \mathrm{~mm}, 62.3 \%$ $(n=48)>1 \mathrm{~mm}$, respectively. The examination of the postoperative specimen showed an infiltration depth of $\leq 1 \mathrm{~mm}$ in $28.6 \%(n=22)$ of cases and $>1 \mathrm{~mm}$ in $71.4 \%(n=55)$, respectively.

Among the study cohort $89.6 \%(n=69)$ of the patients showed at least a difference of $1 \mathrm{~mm}$ within depths of stromal invasion comparing the pre- and postoperative specimen (Fig. 1). Within seventeen patients the necessity of lymph node biopsies was underestimated- showing infiltration depth $\leq 1 \mathrm{~mm}$ within preoperative taken punch biopsy and showing infiltration depth $>1 \mathrm{~mm}$ within the surgical
Table 1 Patient collective

\begin{tabular}{|c|c|c|}
\hline Characteristic & $n$ & $\%$ \\
\hline \multicolumn{3}{|l|}{ Age (years) } \\
\hline$\leq 30$ & 4 & 5.2 \\
\hline $31-40$ & 9 & 11.7 \\
\hline $41-50$ & 12 & 15.6 \\
\hline $51-60$ & 20 & 26.0 \\
\hline $61-70$ & 16 & 20.8 \\
\hline $71-80$ & 9 & 11.7 \\
\hline$>80$ & 7 & 9.1 \\
\hline \multicolumn{3}{|l|}{$\operatorname{BMI}\left(\mathrm{kg} / \mathrm{m}^{2}\right)$} \\
\hline $17 \leq 18.5$ & 1 & 1.3 \\
\hline $18.5 \leq 25$ & 33 & 42.9 \\
\hline $25 \leq 30$ & 24 & 31.2 \\
\hline $30 \leq 35$ & 7 & 9.1 \\
\hline$>35$ & 12 & 15.6 \\
\hline \multicolumn{3}{|l|}{ T-Status } \\
\hline pT1a & 12 & 15.6 \\
\hline pT1b & 58 & 75.3 \\
\hline pT2 & 7 & 9.1 \\
\hline \multicolumn{3}{|l|}{ N-Status } \\
\hline pNO & 59 & 76.6 \\
\hline pN1 & 6 & 7.8 \\
\hline pN2 & 5 & 6.5 \\
\hline $\mathrm{pNx}$ & 7 & 9.1 \\
\hline \multicolumn{3}{|l|}{ M-Status } \\
\hline M0 & 63 & 81.8 \\
\hline $\mathrm{Mx}$ & 14 & 18.2 \\
\hline \multicolumn{3}{|l|}{ G-Status } \\
\hline G1 & 3 & 3.9 \\
\hline $\mathrm{G} 2$ & 59 & 76.6 \\
\hline G3 & 13 & 16.9 \\
\hline $\mathrm{Gx}$ & 2 & 2.6 \\
\hline
\end{tabular}

specimen. In $22.1 \%$ of the cases preoperative biopsies were not able to predict the need for lymph node surgery.

\section{Discussion}

Squamous cell carcinoma of the vulva accounts for $5 \%$ of female genital cancers and is currently showing a rising incidence in younger women (Mahner et al. 2015; Thangarajah et al. 2019). One important factor in reducing mortality from vulva cancer is appropriate treatment of inguinal lymph nodes. Sentinel node biopsy was implemented for management of SQCV to reduce morbidity of radical groin dissection such as lymphocele and wound healing complications. It has been proven to be a safe treatment option within early- stage disease (Alkatout et al. 2015; 
Fig. 1 Depth of infiltration/ VIN status in preoperative biopsy and operative specimen (underestimated: punch biopsy showed infiltration depth $\leq 1 \mathrm{~mm}$ and surgical specimen showed $>1 \mathrm{~mm}$ infiltration depth)

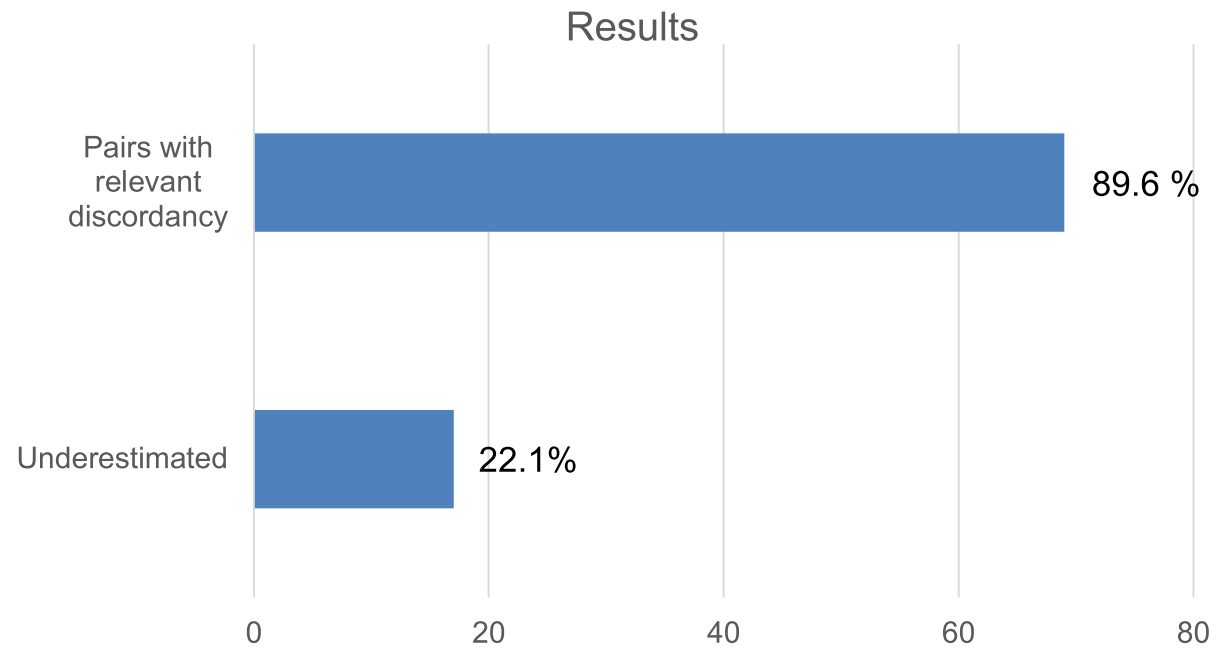

Table 2 Pre- and postoperative infiltration depth in 77 patients

\begin{tabular}{lll}
\hline & Postoperative $\leq 1 \mathrm{~mm}$ & Postoperative $>1 \mathrm{~mm}$ \\
\hline Preoperative $\leq 1 \mathrm{~mm}$ & $15.6 \%(n=12)$ & $22.1 \%(n=17)$ \\
Preoperative $>1 \mathrm{~mm}$ & $13.0 \%(n=10)$ & $49.4 \%(n=38)$ \\
\hline
\end{tabular}

Preoperative infiltration depth: measured in biopsy; postoperative infiltration depth: maximum of infiltration depth in biopsy or surgical tumor specimen

Levenback et al. 2009). Patients undergoing surgery of the vulva for a curative approach of vulva cancer and showing an infiltration depth of $>1 \mathrm{~mm}$ should as well be treated with lymph node surgery. Thus, the decision regarding lymph node biopsies in early stage disease directly depends on preoperative the biopsy.

In this study we were able to show that in most patients a difference of at least $1 \mathrm{~mm}$ between preoperative infiltration depth and stromal invasion within the surgical specimen was noticed. We pointed out, that only in $77.9 \%$ of the patients who should have undergone lymph node surgery based on the postoperative depth of infiltration underwent this necessary procedure. Consequentially in $22.1 \%$ of the cases a second operation was required (see Table 2).

Other studies reviewed whether the depth of infiltration depends on the consulted pathologists and determined the effect of secondary slide reviews of specimen. They showed discrepancies between original and review reports of $0-9 \%$, indicating that slide review should be considered when the infiltration depth is $\leq 1 \mathrm{~mm}$ (Beugeling et al. 2014; Chafe et al. 2000; Chan et al. 1999; Khalifa et al. 2003; Santoso et al. 1998; Selman et al. 1999). It might be another approach to review a slide if the infiltration depth is between 0.8 and $1.2 \mathrm{~mm}$. Nevertheless, it remains questionable whether secondary slide reviews are able to solve the problem of different infiltration depths in the pre- and postoperative specimen. Due to the heterogeneous appearance of the tumor itself a biopsy might not be representative regarding the depth of infiltration. Even with secondary slide reviews patients might still not undergo a required lymph node surgery in their first operation but consequently need to get a second operation.

Other preoperative strategies should be considered to avoid a secondary surgery for lymph node biopsy, not only because of its perioperative risks but also because once the tumor is resected an injection near the tumor is not possible anymore and accuracy of sentinel node procedure might be reduced during a secondary operation. Oncological safety of secondary lymph node surgery remains unclear. It should be the aim of modern disease therapy to develop an optimized, individual patient-related strategy and to reduce morbidity. Prospective studies are necessary to evaluate the liability of preoperative biopsies. Taking bigger preoperative biopsies or multiple biopsies might improof accuracy determining the definite depth of infiltration. It remains elusive whether the size of the tumor should dictate the amount or the size of the biopsies.

\section{Conclusion}

Patients who undergo just tumor resection and no primary inguinal lymph node surgery, based on a preoperative depth of infiltration $\leq 1 \mathrm{~mm}$, should be informed about the risk of a secondary operation for lymph node resection. Based on our study, there is a $22.1 \%$ risk for the need of a secondary surgery. Studies with a larger group of patients should be performed to further explore this issue.

Acknowledgements Open Access funding provided by Projekt DEAL. 
Author contributions All authors contributed to the study conception and design. Material preparation, data collection and analysis were performed by Dr. Caroline Pahmeyer and Dr. Fabinshy Thangarajah, The first draft of the manuscript was written by Dr. Caroline Pahmeyer and all authors commented on previous versions of the manuscript. All authors read and approved the final manuscript.

\section{Compliance with ethical standards}

Conflicts of interest The authors declare they have no conflict or interests/competing interests

Open Access This article is licensed under a Creative Commons Attribution 4.0 International License, which permits use, sharing, adaptation, distribution and reproduction in any medium or format, as long as you give appropriate credit to the original author(s) and the source, provide a link to the Creative Commons licence, and indicate if changes were made. The images or other third party material in this article are included in the article's Creative Commons licence, unless indicated otherwise in a credit line to the material. If material is not included in the article's Creative Commons licence and your intended use is not permitted by statutory regulation or exceeds the permitted use, you will need to obtain permission directly from the copyright holder. To view a copy of this licence, visit http://creativecommons.org/licenses/by/4.0/.

\section{References}

Alkatout I, Schubert M, Garbrecht N, Weigel MT, Jonat W, Mundhenke C, Gunther V (2015) Vulvar cancer: epidemiology, clinical presentation, and management options. Int J Womens Health 7:305-313. https://doi.org/10.2147/ijwh.s68979

AWMF-Leitlinie Stand (2015) S3-Leitlinie: Diagnostik, Therapie und Nachsorge des Vulvakarzinoms und seiner Vorstufen

Beugeling M, Ewing-Graham PC, Mzallassi Z, van Doorn HC (2014) Pathology slide review in vulvar cancer does not change patient management. ISRN Surg 2014:385386. https://doi. org/10.1155/2014/385386

Brinton LA, Thistle JE, Liao LM, Trabert B (2017) Epidemiology of vulvar neoplasia in the NIH-AARP Study. Gynecol Oncol 145:298-304. https://doi.org/10.1016/j.ygyno.2017.02.030

Chafe S, Honore L, Pearcey R, Capstick V (2000) An analysis of the impact of pathology review in gynecologic cancer. Int J Radiat
Oncol Biol Phys 48:1433-1438. https://doi.org/10.1016/s0360 -3016(00)00791-4

Chan YM, Cheung AN, Cheng DK, Ng TY, Ngan HY, Wong LC (1999) Pathology slide review in gynecologic oncology: routine or selective? Gynecol Oncol 75:267-271. https://doi.org/10.1006/ gyno.1999.5567

Khalifa MA, Dodge J, Covens A, Osborne R, Ackerman I (2003) Slide review in gynecologic oncology ensures completeness of reporting and diagnostic accuracy. Gynecol Oncol 90:425-430. https:// doi.org/10.1016/s0090-8258(03)00323-8

Koh W-J, Greer BE, Abu-Rustum NR et al (2017) Vulvar cancer, version 1.2017 , clinical practice guidelines in oncology. J Natl Compr Canc Netw 15(1):92-120. https://doi.org/10.6004/jnccn .2017.0008

Levenback CF et al (2009) Sentinel lymph node biopsy in patients with gynecologic cancers Expert panel statement from the International Sentinel Node Society Meeting, February 21, 2008. Gynecol Oncol 114:151-156. https://doi.org/10.1016/j.ygyno.2009.03.035

Mahner S et al (2015) Systemic treatment of vulvar cancer. Expert Rev Anticancer Ther 15:629-637. https://doi.org/10.1586/14737 140.2015.1037837

Oonk MHM, Planchamp F, Baldwin P et al (2017) European Society of Gynaecological Oncology Guidelines for the management of patients with vulvar cancer. Int J Gynecol Cancer 27(4):832-837. https://doi.org/10.1097/IGC.0000000000000975

RCOG (2014) Guidelines for the diagnosis and management of vulval carcinoma. Royal College of Obstetricians and Gynaecologists, London

Santoso JT, Coleman RL, Voet RL, Bernstein SG, Lifshitz S, Miller D (1998) Pathology slide review in gynecologic oncology. Obstet Gynecol 91:730-734. https://doi.org/10.1016/s0029 $-7844(98) 00032-5$

Selman AE, Niemann TH, Fowler JM, Copeland LJ (1999) Quality assurance of second opinion pathology in gynecologic oncology. Obstet Gynecol 94:302-306. https://doi.org/10.1016/s0029 7844(99)00318-x

Thangarajah F et al (2019) Clinical impact of PD-L1 and PD-1 expression in squamous cell cancer of the vulva. J Cancer Res Clin Oncol 145:1651-1660. https://doi.org/10.1007/s00432-019-02915-1

Publisher's Note Springer Nature remains neutral with regard to jurisdictional claims in published maps and institutional affiliations. 